\title{
Review Article \\ Learner-Directed Nutrition Content for Medical Schools to Meet LCME Standards
}

\author{
Lisa A. Hark, ${ }^{1}$ Darwin D. Deen, ${ }^{2}$ and Gail Morrison ${ }^{3}$ \\ ${ }^{1}$ Department of Research, Wills Eye Hospital, Philadelphia, PA, USA \\ ${ }^{2}$ Sophie Davis School of Biomedical Education, City College of New York, NY, USA \\ ${ }^{3}$ Perelman School of Medicine at the University of Pennsylvania, Philadelphia, PA, USA \\ Correspondence should be addressed to Lisa A. Hark; lhark@willseye.org
}

Received 22 October 2014; Accepted 21 December 2014

Academic Editor: Balakrishnan Nair

Copyright (C) 2015 Lisa A. Hark et al. This is an open access article distributed under the Creative Commons Attribution License, which permits unrestricted use, distribution, and reproduction in any medium, provided the original work is properly cited.

\begin{abstract}
Deficiencies in medical school nutrition education have been noted since the 1960s. Nutrition-related non-communicable diseases, including heart disease, stroke, cancer, diabetes, and obesity, are now the most common, costly, and preventable health problems in the US. Training medical students to assess diet and nutritional status and advise patients about a healthy diet, exercise, body weight, smoking, and alcohol consumption are critical to reducing chronic disease risk. Barriers to improving medical school nutrition content include lack of faculty preparation, limited curricular time, and the absence of funding. Several new LCME standards provide important impetus for incorporating nutrition into existing medical school curriculum as self-directed material. Fortunately, with advances in technology, electronic learning platforms, and web-based modules, nutrition can be integrated and assessed across all four years of medical school at minimal costs to medical schools. Medical educators have access to a self-study nutrition textbook, Medical Nutrition and Disease, Nutrition in Medicine $\odot$ online modules, and the NHLBI Nutrition Curriculum Guide for Training Physicians. This paper outlines how learner-directed nutrition content can be used to meet several US and Canadian LCME accreditation standards. The health of the nation depends upon future physicians' ability to help their patients make diet and lifestyle changes.
\end{abstract}

\section{Introduction}

Deficiencies in nutrition education in medical schools and residency programs have been noted for over 30 years [1-6]. In 1982 and 1995, Weinsier published consensus statements from medical nutrition educators who prioritized nutrition content and stressed its importance in the medical school curriculum $[7,8]$. Professional organizations, medical nutrition experts, and student groups have published reports, articles, book chapters, user's guides, and a congressional mandate urging medical schools to reform curriculum to spend more time integrating nutrition [9-19]. Recommendations were also made by medical nutrition experts after reviewing nutrition content across US Medical Licensing Examinations (USMLE) administered by the National Board of Medical Examiners [20].

As a result of these initiatives, the National Heart, Lung, and Blood Institute (NHLBI) and the National Institute of Diabetes and Digestive and Kidney Diseases (NIDDK) established the Nutrition Academic Award (NAA) Program (http://www.nhlbi.nih.gov/research/training/naa/) [21, 22]. The NAA provided 21 US medical schools with 5-year grants to support nutrition education programs for medical students, medical residents, and clinical faculty [21, 22]. The NAA Curriculum Committee developed the Nutrition Curriculum Guide to Training Physicians, which contains over 200 educational learning objectives that medical students, residents, and physicians in practice should acquire to achieve competency $[23,24]$.

\section{The Problem}

While significant progress was made during the NAA program, ten years later we are facing the same issues. According to the Association of American Medical Schools (AAMC) All School Graduation Surveys, more than $50 \%$ of graduating 
medical students felt their nutrition knowledge was insufficient $[25,26]$. Practicing physicians also feel their nutrition training was inadequate and that they lack the skills to provide effective diet and lifestyle counseling to their patients [27-31]. A review of nutrition content in medical schools shows that, on average, only 4 to 6 hours are devoted to nutrition content over the entire 4-year curriculum [32, 33]. While curriculum hours and teaching methods vary widely among medical schools, nutrition educators have suggested that a minimum of 25 hours are needed to properly train medical students in nutrition [2, 9, 10, 13, 19, 30, 32-34].

According to our experience, lack of faculty to teach nutrition, competing curricular requirements, and the absence of funding for a nutrition curriculum coordinator at each medical school are major factors contributing to the ongoing problem. Fortunately, with advances in technology, electronic textbooks, online learning modules, and nutrition test questions posted on (e)-learning platforms for evaluation, these barriers can easily be overcome at minimal cost to medical schools.

\section{Relevance to Medical Practice}

Studies show that the relevance of the course material to medical practice is critical when integrating nutrition content $[7,8]$. According to the Centers for Disease Control and Prevention (CDC), the majority of US health care costs are now spent on chronic, non-communicable diseases associated with health risk behaviors $[35,36]$. Specifically, heart disease, stroke, cancer, diabetes, obesity, and arthritis are among the most common, costly, and preventable health problems [3740]. As of 2012, about half of all adults, 117 million people, have one or more chronic health conditions [41]. One of four adults has two or more chronic health conditions [41]. Two of these chronic diseases, heart disease and cancer, together, accounted for nearly $48 \%$ of all deaths in 2010 [41]. According to the CDC, $47 \%$ of US adults have at least one of the following major risk factors for heart disease or stroke: high blood pressure, high LDL-cholesterol, or are current smokers [42-47]. Ninety percent of Americans consume too much sodium, increasing their risk of high blood pressure $[48,49]$. With the current obesity epidemic and the costs associated with chronic disease skyrocketing, medical schools need to find creative learning opportunities to ensure that medical students graduate with the ability to recognize the association between lifestyle and chronic disease, take a diet and exercise history, and effectively intervene by promoting a healthy lifestyle [50-52].

Strong evidence indicates that diet, largely through its effect on serum lipids, influences the incidence of heart disease [53-55]. Intake of saturated fat increases LDL-C levels, thereby increasing the risk for coronary heart disease (CHD). Large-scale clinical trials have conclusively shown that reducing serum LDL-C levels reduces the number of acute cardiac events and deaths from CHD in both patients with existing disease and those at risk due to elevated lipids. Updated 2013 guidelines for the assessment of cardiovascular (CV) risk, lifestyle modifications to reduce $\mathrm{CV}$ risk, and management of blood cholesterol, overweight, and obesity in adults have been developed by the American College of Cardiology and the American Heart Association Task Force on Practice Guidelines [53-55]. Diet and lifestyle changes are also the primary focus of the Joint National Committee on the Treatment and Management of Hypertension (JNC8) and the American Diabetes Association Treatment Guidelines [56-58]. The American Cancer Society has published similar guidelines on nutrition and physical activity for cancer prevention [59]. Therefore, training medical students to advise patients to consume a healthy diet, exercise regularly, maintain desired body weight, avoid smoking, and drink alcohol in moderation is critical to reducing morbidity and mortality [42, 53-59].

\section{Role of LCME and Medical Schools}

Medical education programs leading to the MD degree in the US and Canada are accredited by the Liaison Committee on Medical Education (LCME) [60]. LCME accreditation is a peer-reviewed process to determine whether the medical school meets established standards. The LCME has created standards outlined in Functions and Structure of a Medical School, which medical schools must meet to achieve and maintain accreditation [60]. Demonstrating that medical students exhibit these general professional competencies is essential to accreditation and serves as the foundation for life-long learning and proficient medical care [60]. These standards are enforced through annual surveys and regular site visits. The purpose of this paper is to demonstrate how learner-directed nutrition content can be used to meet several US and Canadian LCME accreditation standards.

Several LCME standards provide important opportunities for incorporating nutrition into existing curriculum as self-directed material and to augment curricular content for medical students across all 4 years (Standard 6: Competencies, Curricular Objectives, and Curricular Design; Standard 7: Curricular Content; and Standard 8: Curricular Management, Evaluation, and Enhancement). Liaison Committee on Medical Education (LCME) Standards 6.3, 7.1, 7.2, 7.5, 7.6, and 8.2 for accreditation of medical education programs leading to the MD degree are shown below [60]:

\section{3: self-directed and life-long learning;}

7.1: biomedical, behavioral, social sciences;

7.2: organ systems/life cycle/primary care/prevention/ wellness/symptoms/signs/differential diagnosis, treatment planning, and impact of behavioral/social factors;

7.5: societal problems;

7.6: cultural competence/health care disparities/personal bias;

8.2: use of medical educational program objectives.

These standards are described and nutrition examples are provided to assist with meeting these standards.

Standard 6.3 Self-Directed and Life-Long Learning. "The faculty of a medical school ensures that the medical curriculum 
includes self-directed learning experiences and time for independent study to allow medical students to develop the skills of life-long learning. Self-directed learning involves medical students' self-assessment of learning needs; independent identification, analysis, and synthesis of relevant information; and appraisal of the credibility of information sources" [60].

Nutrition Example. Given the shortage of faculty prepared to teach nutrition and the ability to use relevant clinical material in a variety of basic science courses and clinical clerkships, nutrition content lends itself very well to selfdirected learning and can help promote life-long learning [52]. Originally developed in 1995 as a self-directed nutrition curriculum for medical students at the University of Pennsylvania School of Medicine, the 5th edition of Medical Nutrition and Disease: A Case-Based Approach can be used to meet Standard 6.3 [61-67]. All 13 chapters and 29 cases include at least 4 NAA Curriculum Guide learning objects. The cases begin with a patient vignette covering past medical history, family history, medications, social and diet history, review of systems, physical examination, and laboratory data [67]. Each case includes at least 5 questions as well as the answers to these questions, making this an ideal selfstudy resource. The questions and answers cover physiology, pathophysiology, epidemiology, risk assessment, diagnosis, laboratory evaluation, treatment planning, medical nutrition therapy, prevention, wellness, and counseling issues.

Nutrition in Medicine Modules $\odot$, developed by University of North Carolina School of Medicine, is a comprehensive online medical nutrition curriculum for training current and future health care professionals $[34,68]$. The content for medical students includes the preventive and therapeutic aspects of medical nutrition care for both preclinical and clinical education [68]. The objectives of the Nutrition in Medicine $\odot$ medical school curriculum are to provide a core curriculum in nutrition for medical students that:

(i) includes preventive and therapeutic perspectives of nutrition;

(ii) spans the preclinical and clinical training of physicians;

(iii) presents the biochemical basis of nutrition, nutrition epidemiology, clinical nutrition [including nutrition assessment], and nutrition-related preventive health care;

(iv) uses innovative techniques to excite students about the field of nutrition and can be transportable by medical schools with different types of curricular organization.

In this era of nutrition therapeutics, it is important to prepare students with the basic concepts of nutrition that will provide a foundation for reading the literature and for life-long learning. For example, with ongoing discoveries in the human microbiome project and nutrigenetics, future physicians will need to be prepared for new avenues of therapy with probiotics [69-71]. The rapidly expanding fields of metabolomics, proteomics, and nutrigenetics will likely drive an era of nutrition therapeutics that current medical students will need to understand and take advantage of [6972].

The updated American Board of Medical Specialties (ABMS) Maintenance of Certification (MOC) program is also designed as a comprehensive approach to foster lifelong learning, self-assessment, and quality improvement $[73,74]$. The role of ABMS is to assist the 24 approved medical specialty boards in the development and use of these standards for the ongoing evaluation and certification of physicians. The MOC assures that physicians are committed to life-long learning and competency in a specialty and/or subspecialty by requiring ongoing measurement of six core competencies adopted by ABMS and the Accreditation Council for Graduate Medical Education (ACGME) [74, 75]. These core competencies include (1) patient care, (2) interpersonal and communication skills, (3) professionalism, (4) practice-based learning, (5) systems-based practice, and (6) medical knowledge. At least 10 of the subspecialty boards, including family medicine, internal medicine, $\mathrm{OB} / \mathrm{GYN}$, surgery, pediatrics, preventive medicine, and ophthalmology, among others, need to integrate nutrition training, and a "call for action" has recently been published [76]. The nutrition foundation instilled during medical school, even as self-study curriculum, will facilitate life-long learning and quality patient care and encourage residency and subspecialty training to integrate nutrition concepts [73-76].

Standard 7.1 Biomedical, Behavioral, Social Sciences. "The faculty of a medical school ensures that the medical curriculum includes content from the biomedical, behavioral, and socioeconomic sciences to support medical students' mastery of contemporary scientific knowledge and concepts and the methods fundamental to applying them to the health of individuals and populations" [60].

Nutrition Example. In 2011, AAMC published the report, Behavioral and Social Science Foundations for Future Physicians, indicating that diet, exercise, smoking, and socioeconomic status contribute to at least $50 \%$ of premature morbidity and mortality in the US population and are major contributors to health disparities [77]. The CDC defines health risk behaviors as unhealthy behaviors that individuals can change $[36,38,41,42]$. Four of these health risk behaviorslack of exercise or physical activity, poor nutrition, tobacco use, and drinking too much alcohol-cause much of the illness, suffering, and early deaths related to chronic diseases $[36,38,41,42,46,47,78]$.

In 2011, more than half (52\%) of adults aged 18 years or older did not meet recommendations for aerobic exercise or physical activity [41]. Therefore, medical students should learn to take a diet and physical activity history, at the same time they are learning how to assess tobacco and alcohol intake as part of routine clinical care [52, 67, 68, 79-86]. With inadequate instruction in nutrition, they are not prepared to use the information they gain from a dietary history and will quickly cease collecting the information [87]. These concepts are covered in Medical Nutrition and Disease and Nutrition in Medicine $\odot$ modules as part of nutrition assessment $[67,68]$. As students work through the various case vignettes, they see 
how clinical nutrition and dietary change can be applied to the medical problems they are learning to understand and manage (Table 1).

Standard 7.2 Organ Systems/Life Cycle/Primary Care/Prevention/Wellness/Symptoms/Signs/Differential Diagnosis, Treatment Planning, and Impact of Behavioral/Social Factors. "The faculty of a medical school ensures that the medical curriculum includes content and clinical experiences related to each organ system; each phase of the human life cycle; continuity of care; and preventive, acute, chronic, rehabilitative, end-oflife, and primary care in order to prepare students to [60]:

(i) recognize wellness, determinants of health, and opportunities for health promotion and disease prevention;

(ii) recognize and interpret symptoms and signs of disease;

(iii) develop differential diagnoses and treatment plans;

(iv) recognize the potential health-related impact on patients of behavioral and socioeconomic factors;

(v) Assist patients in addressing health-related issues involving all organ systems."

Nutrition Example. There are numerous ways nutrition content can be assigned to students, either through lectures, small group sessions, problem-based and case-based learning, webbased modules, or though using e-textbook content $[9,10$, $34,52,67,68,88]$. It is important that nutrition-related clinical cases be used in each phase of the human life cycle, including pregnancy, breast feeding, infant growth and development, childhood, adolescence, adulthood, women's and men's health, and geriatrics including diverse cultures and low socioeconomic groups (Table 1).

Proper nutrition is critical for wellness, has major impact on determinants of health, and provides many opportunities for health promotion and disease prevention education. For example, the role of the Mediterranean diet in the prevention of heart disease; the DASH diet for hypertension and stroke prevention; and healthy eating and exercise strategies for cancer prevention and diabetes management [58, 59, 8991]. Recognizing and interpreting symptoms and signs of nutrition-related diseases including malnutrition, overweight and obesity, and eating disorders can be integrated into physical diagnosis courses. Nutrition assessment and counseling needs to be a part of the treatment plan for disorders across many organ systems including cardiovascular, pulmonary, endocrine, hematology, oncology, renal, neurology, and gastroenterology $[24,67,68]$. Taking a diet, exercise, and weight history; calculating body mass index (BMI); measuring waistto-hip ratio; and understanding and interpreting relevant laboratory measures are critical skills for students to acquire $[7,8,23,24,67,68]$.

The chapters and cases in Medical Nutrition and Disease and the online modules in Nutrition in Medicine $@$ cover each organ system; each phase of the human life cycle; continuity of care; and preventive, acute, chronic, and primary care issues as described in Standard 7.2 [67, 68]. Several examples include the association between obesity and sleep apnea, insulin resistance and diabetes, nutritional anemias, and malnutrition and depression.

Standard 7.5 Societal Problems. "The faculty of a medical school ensure that the medical curriculum includes instruction in the diagnosis, prevention, appropriate reporting, and treatment of the medical consequences of common societal problems" [60].

Nutrition Example. Obesity is a complex, multifactorial disease that has become a societal problem and increasingly common among adults and children worldwide [92, 93]. Once considered a problem only in developed countries, overweight and obesity are now dramatically on the rise in developing countries as well, particularly in urban settings $[35,38]$. Obese individuals have an increased risk of diabetes, cardiovascular disease, hyperlipidemia, hypertension, stroke, gallbladder disease, sleep apnea, osteoarthritis, respiratory problems, and certain types of cancers (endometrial, breast, prostate, and colon), all of which increase their mortality $[67,93]$. According to the CDC, seven out of ten deaths among Americans each year result from chronic diseases [3638]. Obesity related conditions such as heart disease, type 2 diabetes, stroke, and certain types of cancer account for more than $50 \%$ of preventable deaths each year [36-38, 42].

Teaching medical students about obesity and diabetes, potentially as themes, can span the entire curriculum across many disciplines [94-97]. There are opportunities in year 1 during history taking and physical exam courses; year 2 during psychiatry, cardiology, endocrinology, pulmonary, gastroenterology, and ophthalmology courses; year 3 during OB/GYN, medicine, family medicine, ophthalmology, and surgery clerkships, and during electives and subinternships (Table 1) [67].

Standard 7.6 Cultural Competence/Health Care Disparities/ Personal Bias. "The faculty of a medical school ensures that the medical curriculum provides opportunities for medical students to learn to recognize and appropriately address gender and cultural biases in themselves, in others, and in the health care delivery process. The medical curriculum includes instruction regarding the following [60]:

(i) the manner in which people of diverse cultures and belief systems perceive health and illness and respond to various symptoms, diseases, and treatments;

(ii) the basic principles of culturally competent health care;

(iii) the recognition and development of solutions for health care disparities;

(iv) the importance of meeting the health care needs of medically underserved populations;

(v) the development of core professional attributes (e.g., altruism and accountability) needed to provide effective care in a multidimensionally diverse society." 
TABLE 1: Integration of Medical Nutrition and Disease content across the medical school curriculum to meet LCME standards.

\begin{tabular}{|c|c|c|c|c|c|c|}
\hline & Content title & Medical school course & Year 1 & Year 2 & Year 3 & Year 4 \\
\hline \multirow{3}{*}{ Chapter 1} & \multirow{3}{*}{ Overview of nutrition assessment in clinical care } & Biochemistry & $\mathrm{x}$ & - & - & - \\
\hline & & History taking & $\mathrm{x}$ & - & - & - \\
\hline & & Physical exam & - & $\mathrm{x}$ & - & - \\
\hline \multirow{3}{*}{ Case 1} & \multirow{3}{*}{ Obesity and metabolic syndrome } & Cardiovascular & - & $\mathrm{x}$ & - & - \\
\hline & & Medicine & - & - & $\mathrm{x}$ & $\mathrm{x}$ \\
\hline & & Family medicine & - & - & $\mathrm{x}$ & $\mathrm{x}$ \\
\hline Case 2 & Bariatric surgery and obesity & Surgery & - & - & $\mathrm{x}$ & $\mathrm{x}$ \\
\hline \multirow{2}{*}{ Chapter 2} & \multirow{2}{*}{ Vitamin, minerals, and dietary supplements } & Biochemistry & $\mathrm{x}$ & - & - & - \\
\hline & & Pharmacology & - & $\mathrm{x}$ & - & - \\
\hline \multirow{3}{*}{ Case 1} & \multirow{3}{*}{ Iron deficiency anemia in women } & Hem/oncology & - & $\mathrm{x}$ & - & - \\
\hline & & Medicine & - & - & $\mathrm{x}$ & $\mathrm{x}$ \\
\hline & & Family medicine & - & - & $\mathrm{x}$ & $\mathrm{x}$ \\
\hline Case 2 & Drug-herb interaction with St. John's wort & Pharmacology & $\mathrm{x}$ & $\mathrm{x}$ & - & - \\
\hline \multirow{2}{*}{ Case 3} & \multirow{2}{*}{ Nutrient deficiencies and lead poisoning in children } & Pharmacology & - & $\mathrm{x}$ & - & - \\
\hline & & Pediatrics & - & - & $\mathrm{x}$ & $\mathrm{x}$ \\
\hline \multirow{2}{*}{ Chapter 3} & \multirow{2}{*}{ Pregnancy and lactation } & Endo/reproduction & - & $\mathrm{x}$ & - & - \\
\hline & & OB/gynecology & - & - & $\mathrm{x}$ & $\mathrm{x}$ \\
\hline \multirow{3}{*}{ Case 1} & \multirow{3}{*}{ Prevention of neural tube defects } & Embryology & $\mathrm{x}$ & - & - & - \\
\hline & & Biochemistry & $\mathrm{x}$ & - & - & - \\
\hline & & OB/gynecology & - & - & $\mathrm{x}$ & $\mathrm{x}$ \\
\hline \multirow{3}{*}{ Case 2} & \multirow{3}{*}{ Encouraging breast feeding } & Endo/reproduction & - & $\mathrm{x}$ & - & - \\
\hline & & Pediatrics & - & - & $\mathrm{x}$ & $\mathrm{x}$ \\
\hline & & OB/gynecology & - & - & $\mathrm{x}$ & $\mathrm{x}$ \\
\hline Chapter 4 & Infants, children, and adolescents & Pediatrics & - & $\mathrm{x}$ & $\mathrm{x}$ & $\mathrm{x}$ \\
\hline \multirow{3}{*}{ Case 1} & \multirow{3}{*}{ Overweight child with insulin resistance } & Biochemistry & $\mathrm{x}$ & - & - & - \\
\hline & & Endocrinology & - & $\mathrm{x}$ & $\mathrm{x}$ & $\mathrm{x}$ \\
\hline & & Pediatrics & - & - & $\mathrm{x}$ & $\mathrm{x}$ \\
\hline \multirow{2}{*}{ Case 2} & \multirow{2}{*}{ Malnutrition and refeeding syndrome in children } & Pediatrics & - & - & $\mathrm{x}$ & $\mathrm{x}$ \\
\hline & & Surgery & - & - & $\mathrm{x}$ & $\mathrm{x}$ \\
\hline \multirow{2}{*}{ Case 3} & Eating disorder in adolescent athlete & Psychiatry & - & $\mathrm{x}$ & - & $\mathrm{x}$ \\
\hline & & Pediatrics & - & - & $\mathrm{x}$ & $\mathrm{x}$ \\
\hline Chanter 5 & Older adults & Medicine/geriatrics & - & - & $\mathrm{x}$ & $\mathrm{x}$ \\
\hline Cnapter 5 & Order adurts & Family medicine & - & - & $\mathrm{x}$ & $\mathrm{x}$ \\
\hline Case 1 & Depression and malnutrition & Psychiatry & - & $\mathrm{x}$ & $\mathrm{x}$ & $\mathrm{x}$ \\
\hline & & Geriatrics & - & - & $\mathrm{x}$ & $\mathrm{x}$ \\
\hline Case 2 & Macular degeneration & Ophthalmology & - & - & $\mathrm{x}$ & $\mathrm{x}$ \\
\hline case 2 & vracurar degenteration & Geriatrics & - & - & $\mathrm{x}$ & $\mathrm{x}$ \\
\hline Case 3 & Menopause and weight gain & Medicine/geriatrics & - & - & $\mathrm{x}$ & $\mathrm{x}$ \\
\hline & & Family medicine & - & - & $\mathrm{x}$ & $\mathrm{x}$ \\
\hline & & Cardiovascular & - & $\mathrm{x}$ & - & - \\
\hline Chapter 6 & Cardiovascular disease & Medicine/cardiology & - & - & $\mathrm{x}$ & $\mathrm{x}$ \\
\hline & & Family medicine & - & - & $\mathrm{x}$ & $\mathrm{x}$ \\
\hline & & Cardiovascular & - & $\mathrm{x}$ & - & - \\
\hline Case 1 & Disorders of lipid metabolism & Medicine/Cardiology & - & - & $\mathrm{x}$ & $\mathrm{x}$ \\
\hline & & Family medicine & - & - & $\mathrm{x}$ & $\mathrm{x}$ \\
\hline & & Cardiovascular & - & $\mathrm{x}$ & - & - \\
\hline Case 2 & Hypertension and lifestyle modifications & Medicine/cardiology & - & - & $\mathrm{x}$ & $\mathrm{x}$ \\
\hline & & Family medicine & - & - & $\mathrm{x}$ & $\mathrm{x}$ \\
\hline
\end{tabular}


TABle 1: Continued.

\begin{tabular}{|c|c|c|c|c|c|c|}
\hline & Content title & Medical school course & Year 1 & Year 2 & Year 3 & Year 4 \\
\hline \multirow{4}{*}{ Case 3} & \multirow{4}{*}{ Metabolic syndrome and LP(a) genetic defect in Asian Indian man } & Genetics & $\mathrm{x}$ & - & - & - \\
\hline & & Cardiovascular & - & $\mathrm{x}$ & - & - \\
\hline & & Medicine/cardiology & - & - & $\mathrm{x}$ & $\mathrm{x}$ \\
\hline & & Family medicine & - & - & $\mathrm{x}$ & $\mathrm{x}$ \\
\hline \multirow{3}{*}{ Chapter 7} & \multirow{3}{*}{ Gastrointestinal disease } & Gastroenterology & - & $\mathrm{x}$ & - & - \\
\hline & & Medicine/GI & - & - & $\mathrm{x}$ & $\mathrm{x}$ \\
\hline & & Family medicine & - & - & $\mathrm{x}$ & $\mathrm{x}$ \\
\hline \multirow{4}{*}{ Case 1} & \multirow{4}{*}{ Alcohol and vitamin deficiencies } & Biochemistry & $\mathrm{x}$ & - & - & - \\
\hline & & Physiology & $\mathrm{x}$ & - & - & - \\
\hline & & Medicine/GI & - & - & $\mathrm{x}$ & $\mathrm{x}$ \\
\hline & & Family medicine & - & - & $\mathrm{x}$ & $\mathrm{x}$ \\
\hline \multirow{2}{*}{ Case 2} & \multirow{2}{*}{ Malabsorption } & Gastroenterology & - & $\mathrm{x}$ & - & - \\
\hline & & Surgery/GI & - & - & $\mathrm{x}$ & $\mathrm{x}$ \\
\hline \multirow{4}{*}{ Case 3} & \multirow{4}{*}{ Celiac disease } & Gastroenterology & - & $\mathrm{x}$ & - & - \\
\hline & & Medicine/GI & - & - & $\mathrm{x}$ & $\mathrm{x}$ \\
\hline & & Family medicine & - & - & $\mathrm{x}$ & $\mathrm{x}$ \\
\hline & & Pediatrics & - & - & $\mathrm{x}$ & $\mathrm{x}$ \\
\hline \multirow{4}{*}{ Chapter 8} & \multirow{4}{*}{ Endocrine disease } & Endocrinology & - & $\mathrm{x}$ & - & - \\
\hline & & Medicine/endocrine & - & - & $\mathrm{x}$ & $\mathrm{x}$ \\
\hline & & Family medicine & - & - & $\mathrm{x}$ & $\mathrm{x}$ \\
\hline & & Pediatrics & - & - & $\mathrm{x}$ & $\mathrm{x}$ \\
\hline \multirow{5}{*}{ Case 1} & \multirow{5}{*}{ Type 1 diabetes and diabetic ketoacidosis } & Biochemistry & $\mathrm{x}$ & - & - & - \\
\hline & & Endocrinology & - & $\mathrm{x}$ & - & - \\
\hline & & Medicine/endocrine & - & - & $\mathrm{x}$ & $\mathrm{x}$ \\
\hline & & Family medicine & - & - & $\mathrm{x}$ & $\mathrm{x}$ \\
\hline & & Pediatrics & - & - & $\mathrm{x}$ & $\mathrm{x}$ \\
\hline \multirow{4}{*}{ Case 2} & \multirow{4}{*}{ Type 2 diabetes } & Endocrinology & - & $\mathrm{x}$ & - & - \\
\hline & & Medicine/endocrine & - & - & $\mathrm{x}$ & $\mathrm{x}$ \\
\hline & & Family medicine & - & - & $\mathrm{x}$ & $\mathrm{x}$ \\
\hline & & Pediatrics & - & - & $\mathrm{x}$ & $\mathrm{x}$ \\
\hline \multirow{5}{*}{ Case 3} & \multirow{5}{*}{ Polycystic ovarian syndrome } & Endo/reproduction & - & $\mathrm{x}$ & - & - \\
\hline & & Medicine/endocrine & - & - & $\mathrm{x}$ & $\mathrm{x}$ \\
\hline & & Family medicine & - & - & $\mathrm{x}$ & $\mathrm{x}$ \\
\hline & & Pediatrics & - & - & $\mathrm{x}$ & $\mathrm{x}$ \\
\hline & & OB/gynecology & - & - & $\mathrm{x}$ & $\mathrm{x}$ \\
\hline \multirow{4}{*}{ Chapter 9} & \multirow{4}{*}{ Pulmonary disease } & Pulmonary & - & $\mathrm{x}$ & - & - \\
\hline & & Medicine/pulmonary & - & - & $\mathrm{x}$ & $\mathrm{x}$ \\
\hline & & Family medicine & - & - & $\mathrm{x}$ & $\mathrm{x}$ \\
\hline & & Pediatrics & - & - & $\mathrm{x}$ & $\mathrm{x}$ \\
\hline & & Pulmonary & - & $\mathrm{x}$ & - & - \\
\hline Case 1 & Chronic obstructive pulmonary disease & Medicine/pulmonary & - & - & $\mathrm{x}$ & $\mathrm{x}$ \\
\hline & & Family Medicine & - & - & $\mathrm{x}$ & $\mathrm{x}$ \\
\hline & & Pediatrics & - & - & $\mathrm{x}$ & $\mathrm{x}$ \\
\hline & & Pulmonary & - & $\mathrm{x}$ & - & - \\
\hline Case 2 & Obstructive sleen annea and metabolic svndrome & Medicine/pulmonary & - & - & $\mathrm{x}$ & $\mathrm{x}$ \\
\hline Case 2 & Oostructive steep apnea and metaoonc synarome & Family medicine & - & - & $\mathrm{x}$ & $\mathrm{x}$ \\
\hline & & Pediatrics & - & - & $\mathrm{x}$ & $\mathrm{x}$ \\
\hline & & Pulmonary & - & $\mathrm{x}$ & - & - \\
\hline Case 3 & Cystic fibrosis & Medicine/pulmonary & - & - & $\mathrm{x}$ & $\mathrm{x}$ \\
\hline Case 3 & Cystic ilorosis & Family medicine & - & - & $\mathrm{x}$ & $\mathrm{x}$ \\
\hline & & Pediatrics & - & - & $\mathrm{x}$ & $\mathrm{x}$ \\
\hline
\end{tabular}


TABle 1: Continued.

\begin{tabular}{|c|c|c|c|c|c|c|}
\hline & Content title & Medical school course & Year 1 & Year 2 & Year 3 & Year 4 \\
\hline \multirow{3}{*}{ Chapter 10} & \multirow{3}{*}{ Renal disease } & Nephrology & - & $\mathrm{x}$ & - & - \\
\hline & & Medicine & - & - & $\mathrm{x}$ & $\mathrm{x}$ \\
\hline & & Family medicine & - & - & $\mathrm{x}$ & $\mathrm{x}$ \\
\hline \multirow{3}{*}{ Case 1} & \multirow{3}{*}{ Chronic renal failure advancing to dialysis } & Nephrology & - & $\mathrm{x}$ & - & - \\
\hline & & Medicine & - & - & $\mathrm{x}$ & $\mathrm{x}$ \\
\hline & & Family medicine & - & - & $\mathrm{x}$ & $\mathrm{x}$ \\
\hline \multirow{3}{*}{ Chapter 11} & \multirow{3}{*}{ Cancer prevention and treatment } & Hem/oncology & - & $\mathrm{x}$ & - & - \\
\hline & & Medicine & - & - & $\mathrm{x}$ & $\mathrm{x}$ \\
\hline & & Family medicine & - & - & $\mathrm{x}$ & $\mathrm{x}$ \\
\hline \multirow{4}{*}{ Case 1} & \multirow{4}{*}{ Prevention of colon cancer } & Pathology & $\mathrm{x}$ & $\mathrm{x}$ & - & - \\
\hline & & Hem/oncology & - & $\mathrm{x}$ & - & - \\
\hline & & Medicine & - & - & $\mathrm{x}$ & $\mathrm{x}$ \\
\hline & & Family medicine & - & - & $\mathrm{x}$ & $\mathrm{x}$ \\
\hline \multirow{2}{*}{ Chapter 12} & \multirow{2}{*}{ Enteral nutrition support } & Surgery & - & - & $\mathrm{x}$ & $\mathrm{x}$ \\
\hline & & Medicine/geriatrics & - & - & $\mathrm{x}$ & $\mathrm{x}$ \\
\hline \multirow{2}{*}{ Case 1} & \multirow{2}{*}{ Esophageal cancer and enteral feeding } & Hem/oncology & - & - & $\mathrm{x}$ & $\mathrm{x}$ \\
\hline & & Surgery & - & - & $\mathrm{x}$ & $\mathrm{x}$ \\
\hline \multirow{2}{*}{ Chapter 13} & \multirow{2}{*}{ Parenteral nutrition support } & Surgery & - & - & $\mathrm{x}$ & $\mathrm{x}$ \\
\hline & & Critical care/ICU & - & - & & $\mathrm{x}$ \\
\hline \multirow{2}{*}{ Case 1} & \multirow{2}{*}{ Colon cancer and postoperative care } & Hem/oncology & - & - & $\mathrm{x}$ & $\mathrm{x}$ \\
\hline & & Critical care/ICU & - & - & $\mathrm{x}$ & $\mathrm{x}$ \\
\hline
\end{tabular}

Source: Lisa Hark, PhD, RD; Darwin Deen, MD, MS; and Gail Morrison, MD, 2015. All rights reserved.

Nutrition Example. In 2010, with the passage of the Patient Protection and Affordable Care Act, the National Center on Minority Health and Health Disparities was redesignated an institute (NIMHD) at the National Institutes of Health (NIH) [98]. The NIMHD conducts research and brings attention to the unequal burden of illness and death experienced by racial and ethnic minorities and rural and poor populations in the US [98]. For example, African Americans are more likely to present with obesity and hypertension $[56,57,99,100]$. Among women, the age-adjusted prevalence of overweight or obesity among racial and ethnic minorities is higher among non-Hispanic black and Mexican-American women than among non-Hispanic white women [38]. According to the CDC, non-Hispanic black adults (17\%) and Hispanic adults (14\%) are less physically active compared to non-Hispanic white adults (23\%) [41, 101].

Assigning self-study cases across the 4-year curriculum can help medical students achieve cultural competency as they progress through medical school [102]. Culturally competent health care builds upon the understanding of these cultural influences and facilitates the development of stronger patient-provider relationships with higher levels of trust.

It is well known that cultural factors and diet-related attitudes and behaviors strongly influence health $[102,103]$. Therefore, the basic principles of culturally competent care include assessing nutritional issues and providing appropriate advice and counseling. The manner in which people of diverse cultures and beliefs system perceive their health is influenced by the person's upbringing, whether or not the person emigrates to a new society, the degree of acculturation to the new society, and the degree to which traditional foods in the culture of origin are available in the new society [102-104]. The meanings and uses ascribed to foods in any particular culture may be unique to that culture and should be considered when prescribing treatment plans $[104,105]$. Culture influences many food-related behaviors including food choice, food purchasing, preparation, where and with whom food is eaten, health beliefs related to food, and adherence to dietary recommendations $[103,104]$. Therefore, understanding the sociocultural context of health for individuals is very important to meet the healthcare needs of all populations, as culture may influence health knowledge, attitudes, and behaviors, including adherence to diet and lifestyle recommendations.

Standard 8.2 Use of Medical Educational Program Objectives. "The faculty of a medical school, through the faculty committee responsible for the medical curriculum, ensures that the medical curriculum uses formally adopted medical education program objectives to guide the selection of curriculum content, to review and revise the curriculum, and to establish the basis for evaluating programmatic effectiveness. The learning objectives of each required course and clerkship are linked to medical education program objectives" [60].

Nutrition Example. Each of the 13 chapters and 29 cases in the 5th edition of Medical Nutrition and Disease includes at least four educational learning objectives based on the Nutrition Curriculum Guide to Training Physicians that was developed by the medical nutrition educators from the NAA Curriculum Committee (http://www.nhlbi.nih.gov/research/ training/naa/products/curr_gde/index.htm) [23, 24]. These 
learning objectives were designed to be used by medical educators and evaluators, curriculum committees, and deans' offices to assist in creating, evaluating, modifying, and updating nutrition curricula at individual programs (medical schools, residency, and fellowship training programs). The section topics include the following:

(1) practice behavior skills and attitudes;

(2) overview and nutrition basics;

(3) lifespan;

(4) cardiovascular system;

(5) metabolic/endocrine systems;

(6) other organ systems;

(7) nutrition support and contemporary trends.

The learning objectives use language consistent with Bloom's taxonomy and are presented for each level of development of expertise, from medical student through practicing physician. The 200 learning objectives encompass knowledge and practice behavior skills and attitudes, both cognitive and problem-solving. The objectives were submitted to a consensus-generating "Delphi" process to prioritize objectives and rank the top $1 / 3$ of all objectives at each learner level. These objectives provide medical educators with a vetted resource to assist learner development and creation of evaluation strategies.

\section{Conclusion}

Medical educators have access to well-established, self-study resources to teach nutrition, such as Medical Nutrition and Disease 5th Edition, Nutrition in Medicine $\odot$ online modules, and the NHLBI Nutrition Curriculum Guide for Training Physicians $[23,67,68]$. Nutrition topics can be integrated across all four years of medical school and during residency training without significant curricular time or cost. Considering trends in team-based learning, interprofessional education, Maintenance of Certification requirements, and longitudinal learning environments, it is an ideal time to make sure that $100 \%$ of medical students and residents graduate with the nutrition-related knowledge, skills, and positive attitudes needed to help their patients make diet and lifestyle changes to reduce, prevent, treat, and manage acute and chronic diseases [52, 67, 68, 73, 105-109].

Building on previous research, the relevance of the course material to medical practice is the critical requirement to implement a successful nutrition education program for medical students $[4,7,8]$. It is imperative to take advantage of this highly relevant time in society when nutrition content can be successfully incorporated into all medical school curriculum to meet LCME standards as well as ACGME programs for ABMS Maintenance of Certification. The health of the nation depends upon this important training at both the medical school and residency level.

\section{Conflict of Interests}

The authors of this paper are editors and contributors to the textbook Medical Nutrition and Disease.

\section{Acknowledgments}

The authors wish to thank their colleagues for continuing to focus on improving nutrition in medical education at all levels of training.

\section{References}

[1] "American Medical Association concepts of nutrition and health. Council on Scientific Affairs," The Journal of the American Medical Association, vol. 242, no. 21, pp. 2335-2338, 1979.

[2] National Research Council Committee on Nutrition in Medical Education, Nutrition Education in U.S. Medical Schools, The National Academy Press, Washington, DC, USA, 1985.

[3] M. Winick, "Nutrition education in medical schools," The American Journal of Clinical Nutrition, vol. 58, no. 6, pp. 825827, 1993.

[4] R. L. Weinsier, J. R. Boker, C. M. Brooks et al., "Priorities for nutrition content in a medical school curriculum: a national consensus of medical educators," The American Journal of Clinical Nutrition, vol. 50, no. 4, pp. 707-712, 1989.

[5] E. B. Feldman, P. R. Borum, M. DiGirolamo et al., "Creation of a regional medical-nutrition education network," The American Journal of Clinical Nutrition, vol. 49, no. 1, pp. 1-16, 1989.

[6] M. Cooke, D. M. Irby, W. Sullivan, and K. M. Ludmerer, "American medical education 100 years after the flexner report," The New England Journal of Medicine, vol. 355, no. 13, pp. 13391344, 2006.

[7] R. L. Weinsier, "Nutrition education in the medical school: factors critical to the development of a successful program.", The Journal of the American College of Nutrition, vol. 1, no. 3, pp. 219226, 1982.

[8] R. L. Weinsier, "National dairy council award for excellence in medical/dental nutrition education lecture, 1995: medicalnutrition education-factors important for developing a successful program," The American Journal of Clinical Nutrition, vol. 62, no. 4, pp. 837-840, 1995.

[9] R. F. Kushner, F. K. Thorp, J. Edwards, R. L. Weinsier, and C. M. Brooks, "Implementing nutrition into the medical curriculum: a user's guide," The American Journal of Clinical Nutrition, vol. 52, no. 2, pp. 401-403, 1990.

[10] M. Kohlmeier and S. H. Zeisel, "Teaching preventive nutrition in medical schools," in Preventive Nutrition: The Comprehensive Guide for Health Professionals, A. Bendich and R. J. Deckelbaum, Eds., pp. 889-899, Humana Press, Totowa, NJ, USA, 3rd edition, 2005.

[11] L. Hark, Medical Nutrition Education Initiatives in the US. Nutricion Clinical, Editorial Medical Panamericana, 2002.

[12] Report of the Ad Hoc Committee of Deans, Education Doctors to Provide High Quality Medical Care: A Vision for Medical Education in the United States, Association of American Medical Colleges, Washington, DC, USA, 2004.

[13] N. F. Krebs and L. E. Primak, "Comprehensive integration of nutrition into medical training," The American Journal of Clinical Nutrition, vol. 83, no. 4, supplement, pp. 945S-950S, 2006. 
[14] R. A. Bruer, R. E. Schmidt, and T. Chapel, Nutrition Education for Physicians: Alternative Federal Roles for Creating an Improved System, Richard Schmidt Associates, Bethesda, Md, USA, 1993.

[15] C. H. Davis, "The report to Congress on the appropriate federal role in assuring access by training in nutrition," Public Health Reports, vol. 109, no. 6, pp. 824-826, 1994.

[16] "National Nutrition Monitoring and Related Research Act of 1990," PubL No. 1101-445/HR1608, Section 302, 1990.

[17] "Report of the American Medical Student Association's Nutrition Curriculum Project. Essentials of nutrition education in medical schools: a national consensus," The American Journal of Clinical Nutrition, vol. 65, pp. 1559-1561, 1997.

[18] D. M. Irby, M. Cooke, and B. C. O’Brien, “Calls for reform of medical education by the Carnegie Foundation for the advancement of teaching: 1910 and 2010," Academic Medicine, vol. 85, no. 2, pp. 220-227, 2010.

[19] W. A. Walker, "Innovative teaching strategies for training physicians in clinical nutrition: an overview," Journal of Nutrition, vol. 133, supplement 2, pp. 541S-543S, 2003.

[20] L. A. Hark, C. Iwamoto, D. E. Melnick et al., "Nutrition coverage on medical licensing examinations in the United States," The American Journal of Clinical Nutrition, vol. 65, no. 2, pp. 568571, 1997.

[21] T. A. Pearson, E. J. Stone, S. M. Grundy, P. E. McBride, L. van Horn, and B. W. Tobin, "Translation of nutritional sciences into medical education: the Nutrition Academic Award Program," The American Journal of Clinical Nutrition, vol. 74, no. 2, pp. 164-170, 2001.

[22] Nutrition Academic Award (NAA), Program at the National Heart, Lung, and Blood Institute, http://www.nhlbi.nih.gov/ research/training/naa/.

[23] Curriculum Committee of the Nutrition Academic Award Program, Nutrition Curriculum Guide for Training Physicians, 2014, http://www.nhlbi.nih.gov/research/training/naa/products/curr -gde/index.htm.

[24] B. M. Tobin, M. Smith, R. L. Kushner, L. Hark, and C. Eaton, "Nutrition curriculum guide for training physicians," The FASEB Journal, vol. 15, no. 4, p. A1095, 2001.

[25] Association of American Medical Colleges, Medical School Graduation Questionnaire. All Schools Report, 2005, https:// www.aamc.org/data/gq/allschoolsreports.

[26] D. L. Taren, C. A. Thomson, N. A. Koff et al., "Effect of an integrated nutrition curriculum on medical education, student clinical performance, and student perception of medical-nutrition training," The American Journal of Clinical Nutrition, vol. 73, no. 6, pp. 1107-1112, 2001.

[27] M. L. Vetter, S. J. Herring, M. Sood, N. R. Shah, and A. L. Kalet, "What do resident physicians know about nutrition? An evaluation of attitudes, self-perceived proficiency and knowledge," The Journal of the American College of Nutrition, vol. 27, no. 2, pp. 287-298, 2008.

[28] J. D. Darer, W. Hwang, H. H. Pham, E. B. Bass, and G. Anderson, "More training needed in chronic care: a survey of U.S. physicians," Academic Medicine, vol. 79, no. 6, pp. 541-548, 2004.

[29] R. F. Kushner, "Barriers to providing nutrition counseling by physicians: a survey of primary care practitioners," Preventive Medicine, vol. 24, no. 6, pp. 546-552, 1995.

[30] B. S. Levine, M. M. Wigren, D. S. Chapman, J. F. Kerner, R. L. Bergman, and R. S. Rivlin, "A national survey of attitudes and practices of primary-care physicians relating to nutrition: strategies for enhancing the use of clinical nutrition in medical practice," The American Journal of Clinical Nutrition, vol. 57, no. 2, pp. 115-119, 1993.

[31] M. Flynn, C. Sciamanna, and K. Vigilante, "Inadequate physician knowledge of the effects of diet on blood lipids and lipoproteins," Nutrition Journal, vol. 2, article 19, 2003.

[32] K. M. Adams, M. Kohlmeier, and S. H. Zeisel, "Nutrition education in U.S. medical schools: latest update of a national survey," Academic Medicine, vol. 85, no. 9, pp. 1537-1542, 2010.

[33] K. M. Adams, K. C. Lindell, M. Kohlmeier, and S. H. Zeisel, "Status of nutrition education in medical schools," The American Journal of Clinical Nutrition, vol. 83, no. 4, pp. 941S-944S, 2006.

[34] K. C. Lindell, K. M. Adams, M. Kohlmeier, and S. H. Zeisel, "The evolution of nutrition in medicine, a computer-assisted nutrition curriculum," The American Journal of Clinical Nutrition, vol. 83, no. 4, pp. 956S-962S, 2006.

[35] E. A. Finkelstein, J. G. Trogdon, J. W. Cohen, and W. Dietz, "Annual medical spending attributable to obesity: payer- and service-specific estimates," Health Affairs, vol. 28, no. 5, pp. w822-w831, 2009.

[36] Centers for Disease Control and Prevention, "Death and Mortality," NCHS FastStats Website, http://www.cdc.gov/nchs/ fastats/deaths.htm.

[37] B. W. Ward, J. S. Schiller, and R. A. Goodman, "Multiple chronic conditions among us adults: a 2012 update," Preventing Chronic Disease, vol. 11, no. 4, Article ID 130389, 2014.

[38] Centers for Disease Control and Prevention, "NCHS Data on Obesity. NCHS Fact Sheet," 2014, http://www.cdc.gov/nchs/ data/factsheets/factsheet_obesity.htm.

[39] K. E. Barbour, C. G. Helmick, K. A. Theis et al., "Prevalence of doctor-diagnosed arthritis and arthritis-attributable activity limitation-United States, 2010-2012," Morbidity and Mortality Weekly Report, vol. 62, no. 14, pp. 869-873, 2013.

[40] J. M. Hootman, M. W. Brault, C. G. Helmick, K. A. Theis, and B. S. Armour, "Prevalence and most common causes of disability among adults-United States," Morbidity and Mortality Weekly Report, vol. 58, no. 16, pp. 421-426, 2005.

[41] Centers for Disease Control and Prevention, Division of Nutrition, National Center for Chronic Disease Prevention and Health Promotion, 2014, http://www.cdc.gov/physicalactivity/ data/facts.html.

[42] Centers for Disease Control and Prevention, National Diabetes Fact Sheet, 2011, Centers for Disease Control and Prevention, US Department of Health and Human Services, Atlanta, Ga, USA, 2011, http://www.cdc.gov/diabetes/pubs/pdf/ndfs_2011.pdf.

[43] C. D. Fryar, T. Chen, and X. Li, "Prevalence of uncontrolled risk factors for cardiovascular disease: United States, 1999-2010," NCHS Data Brief 103, National Center for Health Statistics, Centers for Disease Control and Prevention, US Department of Health and Human Services, Hyattsville, Md, USA, 2012.

[44] A. S. Go, D. Mozaffarian, V. L. Roger et al., "Executive summary: heart disease and stroke statistics-2014 update: a report from the American Heart Association," Circulation, vol. 129, no. 3, pp. 399-410, 2014.

[45] US Department of Health and Human Services, The Health Consequences of Smoking-50 Years of Progress: A Report of the Surgeon General, US Department of Health and Human Services, Centers for Disease Control and Prevention, Atlanta, Ga, 
USA, 2014, http://www.surgeongeneral.gov/library/reports/50years-of-progress/index.html.

[46] Centers for Disease Control and Prevention, "Alcohol and Public Health: Alcohol Related Disease Impact (ARDI)," http://apps .nccd.cdc.gov/DACH_ARDI/Default/Default.aspx.

[47] Centers for Disease Control and Prevention, "Alcohol-attributable deaths and years of potential life lost, United States, 2001," Morbidity and Mortality Weekly Report, vol. 53, pp. 866870, 2004.

[48] M. E. Cogswell, Z. Zhang, A. L. Carriquiry et al., "Sodium and potassium intakes among US adults: NHANES 2003-2008," The American Journal of Clinical Nutrition, vol. 96, no. 3, pp. 647657, 2012.

[49] S. S. Yoon, V. Burt, T. Louis, and M. D. Carroll, "Hypertension among adults in the United States, 2009-2010," NCHS Data Brief no. 107, National Center for Health Statistics, Hyattsville, Md, USA, 2012.

[50] A. G. Tsai, D. F. Williamson, and H. A. Glick, "Direct medical cost of overweight and obesity in the USA: a quantitative systematic review," Obesity Reviews, vol. 12, no. 1, pp. 50-61, 2011.

[51] C. Lenders, K. Gorman, H. Milch et al., "A novel nutrition medicine education model: the Boston University experience," Advances in Nutrition, vol. 4, no. 1, pp. 1-7, 2013.

[52] R. F. Kushner, L. Van Horn, C. L. Rock et al., "Nutrition education in medical school: a time of opportunity," The American Journal of Clinical Nutrition, vol. 99, no. 5, pp. 1167S1173S, 2014.

[53] S. S. Gidding, A. H. Lichtenstein, M. S. Faith et al., "Implementing American Heart Association pediatric and adult nutrition guidelines: a scientific statement from the American Heart Association Nutrition Committee of the Council on Nutrition, Physical Activity and Metabolism, Council on Cardiovascular Disease in the Young, Council on Arteriosclerosis, Thrombosis and Vascular Biology, Council on Cardiovascular Nursing, Council on Epidemiology and Prevention, and Council for High Blood Pressure Research," Circulation, vol. 119, no. 8, pp. 1161-1175, 2009.

[54] R. H. Eckel, J. M. Jakicic, J. D. Ard et al., "2013 AHA/ACC guideline on lifestyle management to reduce cardiovascular risk: a report of the American College of Cardiology/American Heart Association Task Force on Practice Guidelines," Journal of the American College of Cardiology, vol. 63, no. 25, part B, pp. 2960-2984, 2014.

[55] R. H. Eckel, J. M. Jakicic, J. D. Ard et al., “2013 AHA/ACC guideline on lifestyle management to reduce cardiovascular risk: a report of the American College of Cardiology/American Heart Association Task Force on Practice Guidelines," Circulation, vol. 129, no. 25, supplement 2, pp. S76-S99, 2014.

[56] P. K. Whelton, L. J. Appel, R. L. Sacco et al., "Sodium, blood pressure, and cardiovascular disease: further evidence supporting the American Heart Association sodium reduction recommendations," Circulation, vol. 126, no. 24, pp. 2880-2889, 2012.

[57] P. A. James, S. Oparil, B. L. Carter et al., "2014 evidence-based guideline for the management of high blood pressure in adults: report from the panel members appointed to the Eighth Joint National Committee (JNC 8)," The Journal of the American Medical Association, vol. 311, no. 5, pp. 507-520, 2014.

[58] A. B. Evert, J. L. Boucher, M. Cypress et al., "Nutrition therapy recommendations for the management of adults with diabetes," Diabetes Care, vol. 36, no. 11, pp. 3821-3842, 2013.
[59] L. H. Kushi, C. Doyle, M. McCullough et al., "American Cancer Society guidelines on nutrition and physical activity for cancer prevention: reducing the risk of cancer with healthy Food choices and physical activity," CA: Cancer Journal for Clinicians, vol. 62, no. 1, pp. 30-67, 2012.

[60] Functions and Structure of a Medical School, "Standards for Accreditation of Medical Education Programs Leading to the MD Degree March 2014," Standards and Elements, July 2015, http://www.lcme.org/publications.htm\#guidelines.

[61] L. Hark, "One programs'experiences in nutrition in medical education," Topics in Clinical Nutrition, vol. 12, no. 3, pp. 42-48, 1997.

[62] L. Hark, "The development of a case-based, integrated curriculum for medical students," The American Journal of Clinical Nutrition, vol. 72, pp. 890S-897S, 2000.

[63] L. Hark and G. Morrison, Eds., Medical Nutrition and Disease: A Case-Based Approach, Blackwell, Malden, Mass, USA, 1st edition, 1995.

[64] L. Hark and G. Morrison, Eds., Medical Nutrition and Disease: A Case-Based Approach, Blackwell Publishing, Malden, Mass, USA, 2nd edition, 1999.

[65] L. Hark and G. Morrison, Eds., Medical Nutrition and Disease: A Case-Based Approach, Wiley-Blackwell, Malden, Mass, USA, 3rd edition, 2005.

[66] L. Hark and G. Morrison, Eds., Medical Nutrition and Disease: A Case-Based Approach, Wiley, Malden, Mass, USA, 4th edition, 2009.

[67] L. Hark, D. D. Deen, and G. Morrison, Eds., Medical Nutrition and Disease: A Case-Based Approach, John Wiley \& Sons, Malden, Mass, USA, 5th edition, 2014.

[68] Nutrition in Medicine, "A comprehensive online medical nutrition curriculum for training current and future healthcare professional," 2014, http://www.nutritioninmedicine.org/.

[69] N. B. Nuno and R. Heuberger, "Nutrigenetic associations with cardiovascular disease," Reviews in Cardiovascular Medicine, vol. 15, no. 3, pp. 217-225, 2014.

[70] N. M. R. Sales, P. B. Pelegrini, and M. C. Goersch, "Nutrigenomics: definitions and advances of this new science," Journal of Nutrition and Metabolism, vol. 2014, Article ID 202759, 6 pages, 2014.

[71] S. Rauschert, O. Uhl, B. Koletzko, and C. Hellmuth, "Metabolomic biomarkers for obesity in humans: a short review," Annals of Nutrition and Metabolism, vol. 64, no. 3-4, pp. 314324, 2014.

[72] E. Viennois, M. T. Baker, B. Xiao, L. Wang, H. Laroui, and D. Merlin, "Longitudinal study of circulating protein biomarkers in inflammatory bowel disease," Journal of Proteomics, vol. 112, pp. 166-179, 2014.

[73] American Board of Medical Specialties, "Setting the standard for quality medical care," http://www.abms.org/.

[74] L. E. Peterson, P. Carek, E. S. Holmboe, J. C. Puffer, E. J. Warm, and R. L. Phillips, "Medical specialty boards can help measure graduate medical education outcomes," Academic Medicine, vol. 89, no. 6, pp. 840-842, 2014.

[75] R. E. Hawkins, R. S. Lipner, H. P. Ham, R. Wagner, and E. S. Holmboe, "American Board of Medical Specialties maintenance of certification: theory and evidence regarding the current framework," Journal of Continuing Education in the Health Professions, vol. 33, supplement 1, pp. S7-S19, 2013.

[76] C. M. Lenders, D. D. Deen, B. Bistrian et al., "Residency and specialties training in nutrition: a call for action," The American 
Journal of Clinical Nutrition, vol. 99, supplement 5, pp. 1174S1183S, 2014.

[77] Report of the Behavioral and Social Science Expert Panel, Behavioral and Social Science Foundations for Future Physicians, Association of American Medical Colleges, Washington, DC, USA, 2011, https://www.aamc.org/download/271020/data/behavioralandsocialsciencefoundationsforfuturephysicians.pdf.

[78] S. S. Lim, T. Vos, A. D. Flaxman et al., "A comparative risk assessment of burden of disease and injury attributable to 67 risk factors and risk factor clusters in 21 regions, 1990-2010: a systematic analysis for the global burden of disease study 2010," The Lancet, vol. 380, no. 9859, pp. 2224-2260, 2012.

[79] E. Frank, L. Elon, and V. Hertzberg, "A quantitative assessment of a 4-year intervention that improved patient counseling through improving medical student health," Medscape General Medicine, vol. 9, no. 2, article 58, 2007.

[80] E. Frank, J. Hedgecock, and L. K. Elon, "Personal health promotion at US medical schools: a quantitative study and qualitative description of deans' and students' perceptions," BMC Medical Education, vol. 4, article 29, 2004.

[81] L. Hark and D. Deen Jr., "Taking a nutrition history: a practical approach for family physicians," The American Family Physician, vol. 59, no. 6, pp. 1521-1528, 1999.

[82] R. F. Kushner, S. Kessler, and W. C. McGaghie, "Using behavior change plans to improve medical student self-care," Academic Medicine, vol. 86, no. 7, pp. 901-906, 2011.

[83] A. Oster, L. Hark, and J. Von Feldt, "An educational module designed to teach second-year medical students about counseling on behavior change," Annals of Behavioral Science and Medical Education, vol. 11, pp. 8-13, 2005.

[84] K. E. Hauer, P. A. Carney, A. Chang, and J. Satterfield, "Behavior change counseling curricula for medical trainees: a systematic review," Academic Medicine, vol. 87, no. 7, pp. 956-968, 2012.

[85] S. Schlair, K. Hanley, C. Gillespie et al., "How medical students' behaviors and attitudes affect the impact of a brief curriculum on nutrition counseling," Journal of Nutrition Education and Behavior, vol. 44, no. 6, pp. 653-657, 2012.

[86] M. Makowske and R. D. Feinman, "Nutrition education: a questionnaire for assessment and teaching," Nutrition Journal, vol. 4, article 2, 2005.

[87] C. O. Walsh, S. I. Ziniel, H. K. Delichatsios, and D. S. Ludwig, "Nutrition attitudes and knowledge in medical students after completion of an integrated nutrition curriculum compared to a dedicated nutrition curriculum: a quasi-experimental study," BMC Medical Education, vol. 11, no. 1, article 58, 2011.

[88] M. S. Edwards and G. C. Rosenfeld, "A problem-based learning approach to incorporating nutrition into the medical curriculum," Medical Education Online, vol. 11, article 10, 2006.

[89] F. M. Sacks, L. P. Svetkey, W. M. Vollmer et al., "Effects on blood pressure of reduced dietary sodium and the Dietary Approaches to Stop Hypertension (DASH) diet. DASH-Sodium Collaborative Research Group," The New England Journal of Medicine, vol. 344, no. 1, pp. 3-10, 2001.

[90] K. Rees, L. Hartley, N. Flowers et al., “'Mediterranean' dietary pattern for the primary prevention of cardiovascular disease," The Cochrane Database of Systematic Reviews, vol. 12, no. 8, Article ID CD009825, 2013.

[91] J. A. Blumenthal, M. A. Babyak, A. Hinderliter et al., "Effects of the DASH diet alone and in combination with exercise and weight loss on blood pressure and cardiovascular biomarkers in men and women with high blood pressure: the ENCORE study," Archives of Internal Medicine, vol. 170, no. 2, pp. 126-135, 2010.

[92] A. B. de Gonzalez, P. Hartge, J. R. Cerhan et al., "Body-mass index and mortality among 1.46 million white adults," The New England Journal of Medicine, vol. 363, no. 23, pp. 2211-2219, 2010.

[93] Institute of Medicine, Accelerating Progress in Obesity Prevention, National Academies Press, Washington, DC, USA, 2012.

[94] G. Rao, L. E. Burke, B. J. Spring et al., "New and emerging weight management strategies for busy ambulatory settings: a scientific statement from the American Heart Association: endorsed by the society of behavioral medicine," Circulation, vol. 124, no. 10, pp. 1182-1203, 2011.

[95] T. V. Mihalynuk, C. S. Scott, and J. B. Coombs, "Self-reported nutrition proficiency is positively correlated with the perceived quality of nutrition training of family physicians in Washington State," The American Journal of Clinical Nutrition, vol. 77, no. 5, pp. 1330-1336, 2003.

[96] T. V. Mihalynuk, R. H. Knopp, C. S. Scott, and J. B. Coombs, "Physician informational needs in providing nutritional guidance to patients," Family Medicine, vol. 36, no. 10, pp. 722-726, 2004.

[97] M. Jay, C. Gillespie, T. Ark et al., "Do internists, pediatricians, and psychiatrists feel competent in obesity care? Using a needs assessment to drive curriculum design," Journal of General Internal Medicine, vol. 23, no. 7, pp. 1066-1070, 2008.

[98] National Institute of Minority Health and Health Disparities, 2014, http://www.nimhd.nih.gov/.

[99] S. Moore, M. Daniel, C. Paquet, L. Dubé, and L. Gauvin, “Association of individual network social capital with abdominal adiposity, overweight and obesity," Journal of Public Health, vol. 31, no. 1, pp. 175-183, 2009.

[100] T. G. K. Bentley, M. Palta, A. J. Paulsen et al., "Race and gender associations between obesity and nine health-related quality-oflife measures," Quality of Life Research, vol. 20, no. 5, pp. 665674, 2011.

[101] Centers for Disease Control and Preventio, Facts on physical activity, 2014, http://www.cdc.gov/physicalactivity/data/facts .html.

[102] L. Hark and H. Delisser, Achieving Cultural Competency: A Case-Based Approach, John Wiley \& Sons, Malden, Mass, USA, 2009, http://www.lisahark.com/.

[103] D. C. S. James, "Factors influencing food choices, dietary intake, and nutrition-related attitudes among African Americans: application of a culturally sensitive model," Ethnicity and Health, vol. 9, no. 4, pp. 349-367, 2004.

[104] L. Hark, K. Ashton, and D. D. Deen, The Nurse Practitioner's Guide to Nutrition, John Wiley \& Sons, Malden, Mass, USA, 2012.

[105] C. O. Airhihenbuwa, S. Kumanyika, T. D. Agurs, A. Lowe, D. Saunders, and C. B. Morssink, "Cultural aspects of African American eating patterns," Ethnicity and Health, vol. 1, no. 3, pp. 245-260, 1996.

[106] A. V. Blue, M. Mitcham, T. Smith, J. Raymond, and R. Greenberg, "Changing the future of health professions: embedding interprofessional education within an academic health center," Academic Medicine, vol. 85, no. 8, pp. 1290-1295, 2010.

[107] Interprofessional Education Collaborative Expert Panel, Core Competencies for Interprofessional Collaborative Practice: Report of an Expert Panel, Interprofessional Education Collaborative, Washington, DC, USA, 2011. 
[108] P. M. Kris-Etherton, S. R. Akabas, C. W. Bales et al., “The need to advance nutrition education in the training of health care professionals and recommended research to evaluate implementation and effectiveness," The American Journal of Clinical Nutrition, vol. 99, no. 5, pp. 1153S-1166S, 2014.

[109] R. A. DiMaria-Ghalili, J. M. Mirtallo, B. W. Tobin, L. Hark, L. van Horn, and C. A. Palmer, "Challenges and opportunities for nutrition education and training in the health care professions: intraprofessional and interprofessional call to action," The American Journal of Clinical Nutrition, vol. 99, no. 5, pp. 1184S1193S, 2014. 

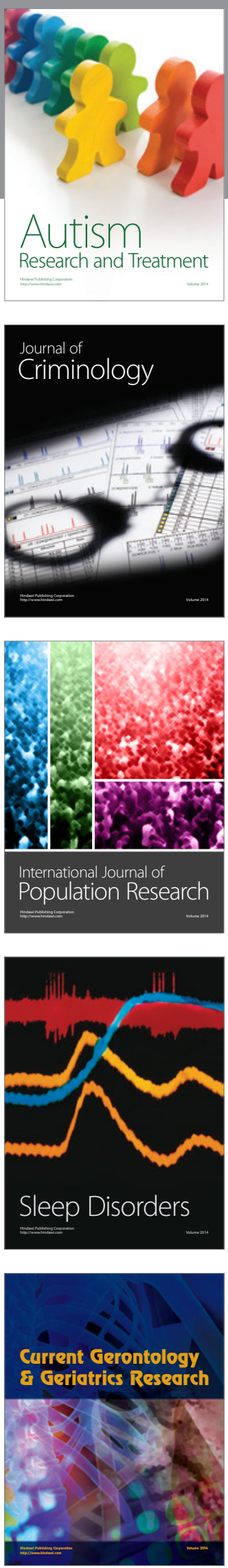
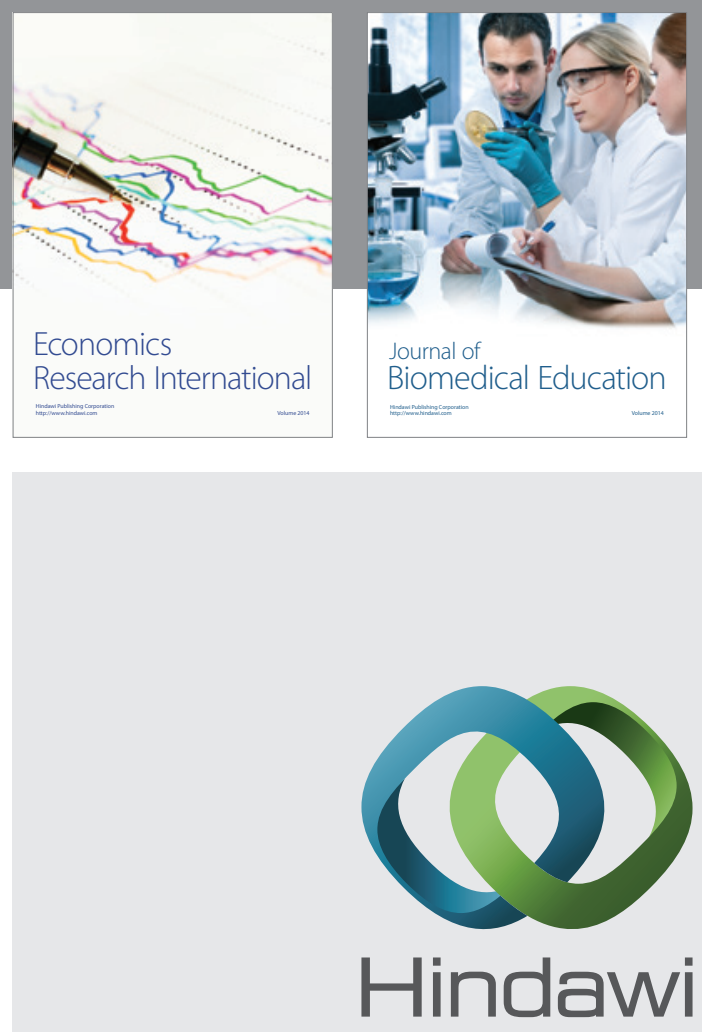

Submit your manuscripts at

http://www.hindawi.com
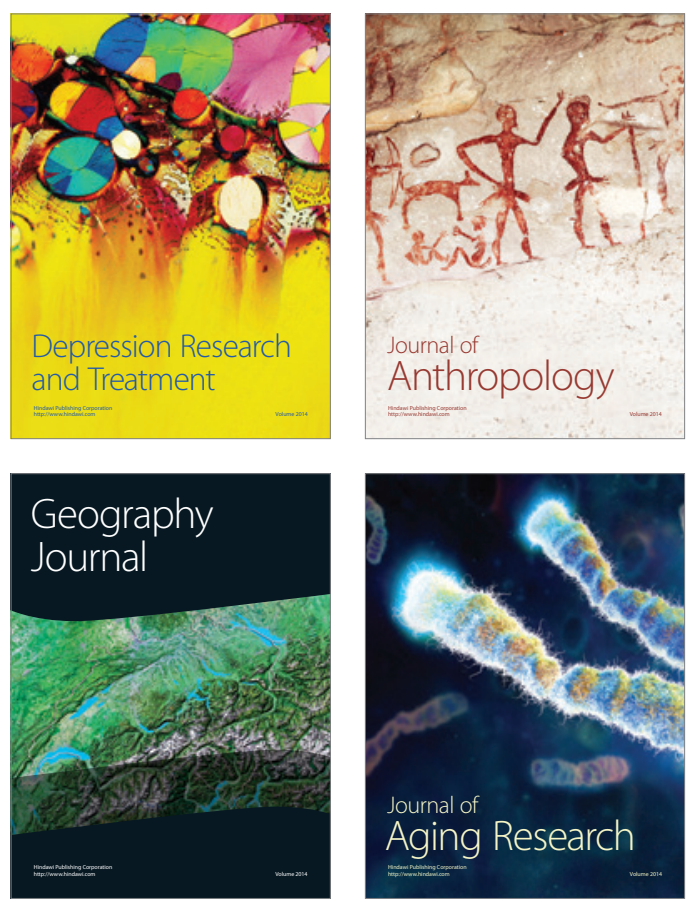
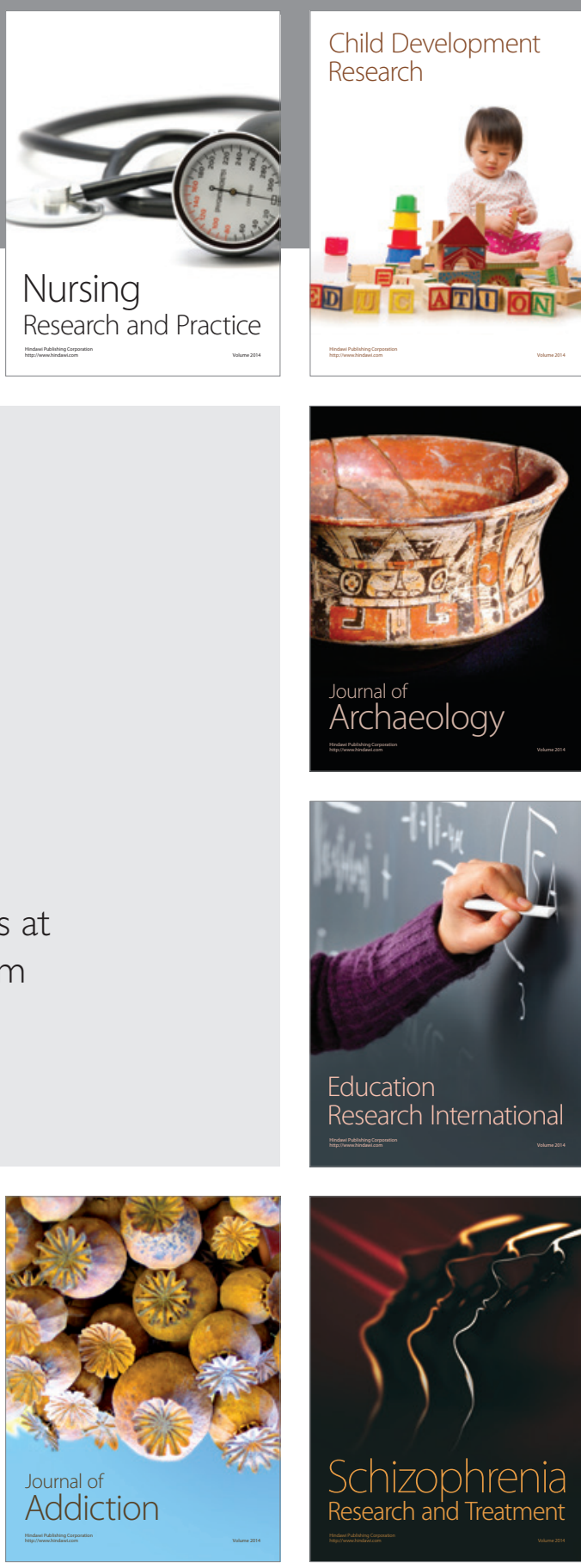

(D)
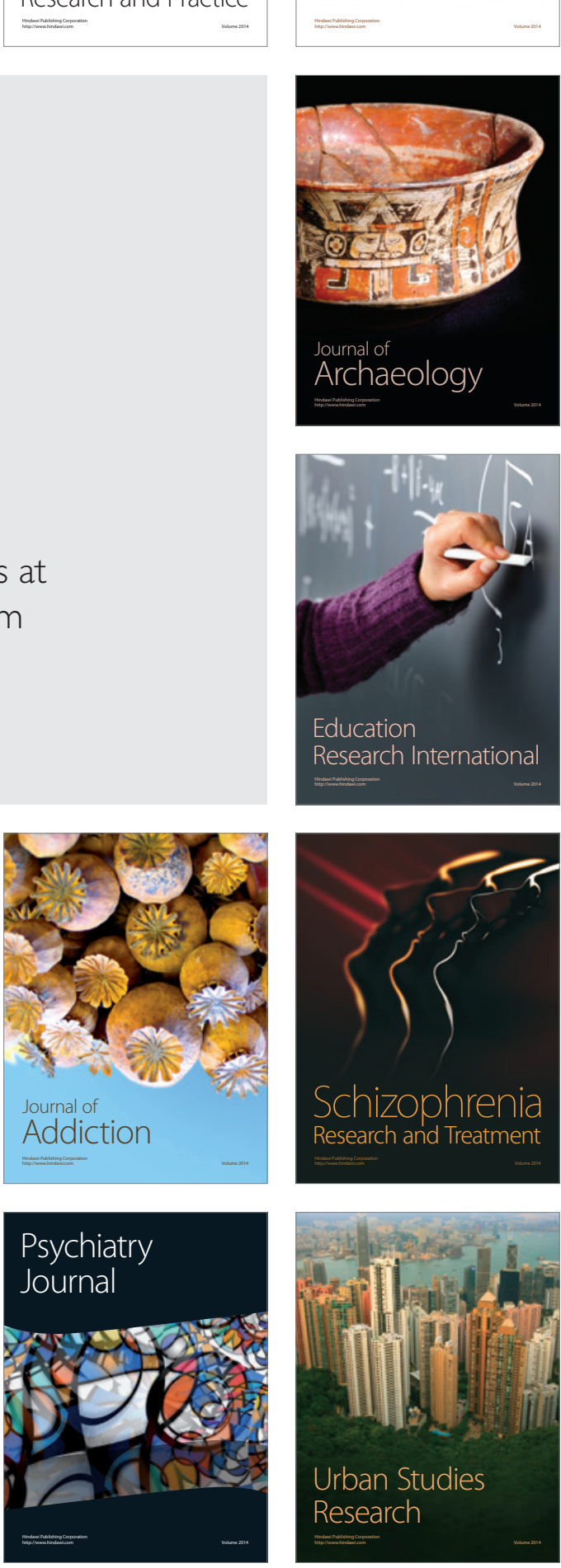